\title{
UNNECESSARY SURGICAL OPERATIONS ON AN UNDIAGNOSED SICKLER IN ABDOMINAL CRISIS: CASE REPORT
}

\author{
E. O. YUSUF AND O. ABEGUNDE
}

(Received 9 August, 2007; Revision Accepted 7 July, 2008)

\begin{abstract}
This is a case of a child that presented with signs and symptoms of acute abdomen. There were scars from previous surgical operations on his abdomen following presentation with similar signs and symptoms suggestive of acute abdomen in two different hospitals.

Furthermore, on careful physical examination some features of sickle cell anaemia were present. Blood was taken for laboratory investigations prior to commencement of intravenous $5 \%$ Dextrose-water. And lo! There was dramatic relief of his symptoms with a beam of smile on his face. Haemoglobin genotype revealed HbSS.
\end{abstract}

KEY WORDS: Sickler, Vaso-occlusive abdominal crisis, laparotomy.

\section{INTRODUCTION}

The chronic haemolysis of sickle cell disease is interspersed with acute exacerbations of the illness called sickle cell crises and the most common is the painful vaso-occlusive crisis (David, 2001).

The pathogenesis of microvascular occlusion, a clinically important component of sickle cell anaemia, is much less certain (Ballas and Mohanda, 1996). However, attempts have been made to explain this phenomenon.

When $\mathrm{HbS}$ is deoxygenated, the molecules of haemoglobin polymerise to form pseudocrystalline structures known as 'tactoids'. These distort the red cell membrane and produce characteristic sickleshaped cells. The polymerisation is reversible when re-oxygenation occurs. The distortion of the red cell membrane may become permanent and the red cell 'irreversibly sickled'. Sickled cells increase blood viscosity, traverse capillaries poorly and tend to obstruct blood flow, thereby increasing the sickling of other cells and eventually stopping the flow (Mackie et al., 1999).

Hebbel et al opined that, it is the normal appearing red cells whose membranes have been altered by repeated cycles of reversible sickling that adhere to the endothelium and cause narrowing of micro vessels; which leads to trapping of the more rigid sickle cells and subsequently vaso-occlusion (Hebbel and Vercellotti, 1997).

\section{CASE REPORT}

Master TB was a 13-year-old secondary school boy residing in Kaduna town with his uncle. He came on a holiday visit to his parents in Benin City. The patient presented to us, accompanied by the

E. O. Yusuf, Dept. of Medical Microbiology, University of Benin teaching Hospital, Benin City, Nigeria.

O. Abegunde, Dept. of Medical Haematology, University of Benin Teaching Hospital, Benin City, Nigeria. 
mother, with a 2 hours history of severe abdominal pain. Mother claimed, that he has had two similar episodes of abdominal pain in the past, following which he had surgical operation on both occasions. The first was in 1993 , in Gombe at the age of 5years and the second was in 1998, in Kaduna at the age of 9years. She however claimed ignorance of the postoperative findings on both occasions. Patient genotype was unknown to the mother, although there was positive history of blood transfusion in the past prior to both surgical operations. She denied any past history of hand and foot syndrome, recurrent bone pains, yellowness of the eyes, and frequent illness or admission in hospital. The child is the third of five children of the mother. The other siblings are well. No history suggestive of sickle cell disease.

On physical examination, he was not pale, anicteric but mildly febrile (Temp. $37.5^{\circ} \mathrm{C}$ ), with frontal bossing, and maxillary prognation, which first raised a suspicion as to the possibility of a sickle cell disease in this patient. There were two surgical scars on his abdomen, with abdominal guarding, tenderness and reduced bowel sounds.

An impression of sickle cell vasoocclusive abdominal crisis was made, to rule out other causes of acute abdomen. Patient was subsequently commenced on intravenous fluid (5\% Dextrose-water), while blood was taken for routine investigations (full blood count, peripheral blood film, electrolytes and urea) as well as haemoglobin genotype. Few minutes after commencement of intravenous fluids abdominal symptoms dramatically resolved.

Peripheral blood film later revealed the presence of sickle cells, nucleated red cells, target cells, Polychromasia and Haemoglobin genotype revealed HbSS. Thick blood smear stained for malaria parasites showed:

MPs ++. Report of other investigations were however normal.

\section{DISCUSSION}

Sickle cell anaemia runs an extremely variable clinical course. At one end of the spectrum, it is characterized by a crippling haemolytic anaemia, interspersed with severe exacerbation, or crisis, yet it may be an extremely mild disorder, which is found only by chance on routine haemotological examination or sometimes punctuated by a crisis as in this case. The reasons are only partly understood for these remarkable differences in phenotypic genetic defect: they include the level of $\mathrm{HbF}$, coinheritance of $\beta$-thalassaemia and of other genetic variants, climate, and probably of most importance, socioeconomic factors such as the availability of early treatment of infection (David, 2001 and Bunn, 1997).

What seems to have precipitated the vaso-occlusive crisis in this case maybe malaria fever coupled with cold, caused by heavy rainfall during the period of presentation of this case.

In children, painful bone crises are extremely common and often difficult to distinguish from acute osteomyelitis. They frequently manifest as the hand \& foot syndrome because of dactylitis of the bones of the hands or feet or both (. Smith, 1996 and Fleming, 1996)

In this case, the mother denied noticing hands and feet syndrome in infancy however; the patient admitted to having pains in the bones of the limbs but this was overshadowed by the abdominal crisis.

The most common of sickle cell crises is the painful vaso-occlusive crises. This is sometimes precipitated by infection, dehydration or exposure to cold, although quite often no underlying cause can be found. The episode starts with vague pain, often in the back or bones of the limbs. The pain gradually worsens and its bizarre distribution may cause a major diagnostic puzzle.

The pain is almost certainly due to occlusion of small vessels with sickled erythrocytes. Marrow aspiration over areas of bone tenderness reveals infarction of the marrow. Occasionally, abdominal pain is the major symptom and this may be associated with distension and rigidity, a picture very similar to an acute abdominal emergency. 
The diagnostic difficulties in distinguishing between an abdominal crisis and a 'Surgical' abdomen are compounded by the fact that the bowel sounds are often very quiet during abdominal crisis. While the painful crisis is extremely distressing, it usually settles down in a few days without any major sequelae.

\section{CONCLUSION}

The case of Master T.B. should be a food for thought for medical personnel in order to avert misdiagnosis that may end up in unnecessary procedures such as a surgical operation that can result in death.

We present this case, for doctors and other healthcare providers to always have sickle-cell disease in abdominal crisis as a differential diagnosis each time they are confronted with acute abdomen especially in children and also to emphasize the importance of careful physical examinations and laboratory investigations even under pressure, as in emergencies.

\section{REFERENCES}

Ballas, S. K., Mohanda, N, 1996. Pathophysiology of Vaso-occlusion. Hematol Oncol Clin North Am; 10: 1221.
Bunn, H. F., 1997. Pathogenesis and treatment of sickle cell disease: $N$. Eng J Med; 337: 762-9.

David, J. W., 2001. Genetic disorders of haemoglobin. In: Postgraduate haematology $.4^{\text {th }}$ ed. Eds, Hoffbrand, A.V., Lewis, S.M., Tuddenham EGD. Arnold, London; 6: 112.

Fleming, A. F., 1996. Haematological diseases in the tropics. In: Manson's Tropical Diseases. $20^{\text {th }}$ ed. WB Saunders; PP 101-173.

Hebbel, R. P. and Vercellotti, G. M., 1997. The endothelial biology of sickle cell disease. J Lab Clin Med; 129: 288.

Mackie, M. J., Ludlam, C. A. and Haynes, A. P., 1999. Diseases of the blood. In: Davidson's Principles and Practice of Medicine. $18^{\text {th }}$ ed. Ed, Haslett, C, Chilvers, E.R., Hunter, J.A.A., Bunn, N.A., Churchill Livingstone; 11: 764 5.

Smith, J. A., 1996. Bone disorders in sickle cell disease. Hematol Oncol Clin North Am; 10: 1345. 